\title{
Natural risks and vulnerability management in urban water supply systems
}

\author{
R. Egea ${ }^{1} \&$ A. Trapote ${ }^{2}$ \\ ${ }^{1}$ Empresa Municipal de Aguas y Saneamiento de Murcia, \\ EMUASA, Spain \\ ${ }^{2}$ Department of Civil Engineering, University of Alicante, Spain
}

\begin{abstract}
In this research, a management model of urban hydraulic infrastructures related to natural hazards is analysed and shown, and different components of the system are characterized and analysed, including pipes, premises and equipment, passive and active devices, communications networks, security systems and surveillance, as well as procedures of planning, operating, and maintenance of the infrastructure. The implementation of the methodology proposed can help to make decisions during the process in real time when you find natural hazards, because through their incorporation into a SIG PLATFORM (System Information Geographic) risk scenario, we can generate a first estimation of incidents and damage of the managed territory.

This management model unifies and integrates all the parameters and variables necessary to anticipate and mitigate the possible catastrophic effects (loss of lives, damage to basic infrastructures). Since it raises possible scenarios, which are updated in real time, we can use as a decision-making tool and as a reliable element, that ensures the operation of this essential system for people and human activities in general. The proposed new designs of equipment and devices increase the operational reliability of the system in the case of hydrogeological catastrophic events due to their functional characteristics.

This methodological tool of management is particularly useful. Furthermore, it can be used, as an urban planning instrument and as a basic element to look up the database for the civil defence, damage mitigation and risk control in the hydraulic urban infrastructure system, increasing resilience, and efficient management to the effects of climate change and the greater variability of natural hazards. Keywords: vulnerability, natural hazards, urban water, risk, reliability.
\end{abstract}




\section{Introduction}

The most used model of analysis and evaluation of hydrogeological risks of the constituent elements of the hydraulic infrastructure is Hazus, based on the methodologies described in the recommendations [1] ATC-13 and ATC-25 and [2]. Based upon this type of methodologies, a model is developed for the evaluation and estimation of hydrogeological risks which, according to a descriptive analysis of operation, proposes likely scenarios of the system that configures a methodology to fully manage urban hydraulic infrastructures. Said methodology is translated into a model of advanced management that will enable a Management Plan of Hydrogeological Risks, from which the directives and alternatives to follow will arise facilitating, thus, the decision-making process when facing these types of event.

With the integrated multi-risks methodology, we can evaluate systematically the following aspects:

- The structural damage caused by the event.

- The cost of the reparation of the urban hydraulic infrastructure.

- The degree of post event operating capacity.

In order to ascertain the direct structural damage of the urban hydraulic infrastructure, that is to say its vulnerability, Hazus proposes the fragility curves analysis of the element, which is different for each scale of damage gradation. Using danger inputs, the fragility curves allow us to obtain the possibilities of occurrence of each state of predefined damage for determined components or equipment. Additionally, the fragility curves specify the damage in terms of probability associated with a determined ground movement for each of the possible damage stages. Some methodologies suggest the unification of probability and obtaining an average parameter that allows a summarised estimation of the damage. Lastly, the Hazus-type methodologies are based on parameters obtained from particular events and environments and their results cannot always be applied to other areas and urban hydraulic infrastructures that have different characteristics and different management systems. That is why the proposed tool defines with higher reliability the operation of the system adjusted to the characteristics of the particular area of analysis.

Estimated repair costs, may arise partly from preventive maintenance, since points or critical facilities analyzed, could be preferred elements of performance to act on in the Plan of Investments of the of Urban Water Infrastructure Agency Manager. At the same time, the repair costs of the damaged infrastructure are directly related to the structural damage suffered and the costs of replacement or execution of the element at risk. The relation or proportionality between repair costs and the damage is obtained from the suggested damage factors [5]. The time of the non-ordinary operation or lack of operation of the system must be evaluated after the catastrophic event and, then, calculate its cost. Nevertheless, there are other costs derived from the lack of operation of the system due to the lack or shortage of supply with the quality required by the rules of this imperative public service, apart from the damage to the image, difficult to measure but still very important. 
Nowadays, the actions to take before and after a catastrophic event do not have a fixed procedure and, in many cases, there is no Plan of Natural Hazards Management or, in its case, of Hydrogeological Risks which should contain the actions to follow and the adequate means depending on the risks scenarios, as well as the interaction with other risks created by the rest of vital infrastructures that can affect the normal functioning of the urban hydraulic infrastructure. These plans could provide live up-to-date information that would suppose an essential tool in the decision-making process. Regarding non-structural damage, which are not included in most computer tools, such as the aforementioned Hazus, they can represent an important variable that produces the non-operation of critical elements of the system, and even the temporary suspension of the service operation.

The suggested methodology proposes, from the phase of design of the actions to take or for repair, the incorporation of absorption and/or movement and anomalies detection devices for the infrastructure, as well as the establishment of a factor of correlation or of proportionality between structural and non-structural damage. In this way, we could have a comprehensive model of evaluation of the vulnerability and damage of the urban hydraulic infrastructure of the element, subsystem and system levels. The non-structural damage is estimated from the definition and characterisation of each facility. In order to do so, we need to take into account the inventory and the normalised and integrated characterisation of the different components located in the system using a relational database integrated in the GIS platform, which will receive constant feedback and will be updated through a specific application of maintenance and exploitation of the facilities. This way, we have a tool to fully manage the urban hydraulic infrastructure, adapted and always evolving, whose analysis parameters are truly representative of the status of a certain facility and of the whole of the system in general. According to the data, an infrastructure cannot suffer important damage on its resistant structure without disrupting the normal operation, but it can present non-structural incidents (electro-mechanic equipment, communication networks, electrical devices, etc.) that prevent the normal function of the infrastructure, or even of the system.

The inputs or parameters values that define the different typologies of hydrogeological risk are, for seismic hazard, the PGA parameter, except for buried infrastructures where the representative parameter is the PGD value. In the particular case of the pipes, both the PGA and the PGD values are required [3] and [4]. For flooding hazard, the suggested parameters that define it best are the rain intensity, the surface runoff or the affected area, as we can see in Table 1. Now, we will summarise the milestones of the current research and the implementation of the suggested methodology:

- Definition and establishment of a management model for the resilient urban hydraulic infrastructure in relation to hydrogeological risks.

- Creation of risk scenarios, and estimation and assessment of damage in the urban hydraulic infrastructure.

- Analysis of the vulnerability of the urban hydraulic infrastructure in the context of climate change. 
- Mitigation of effects on the urban hydraulic infrastructure in relation to hydrogeological risks.

- Planning, development and implantation of resilience in the urban hydraulic system.

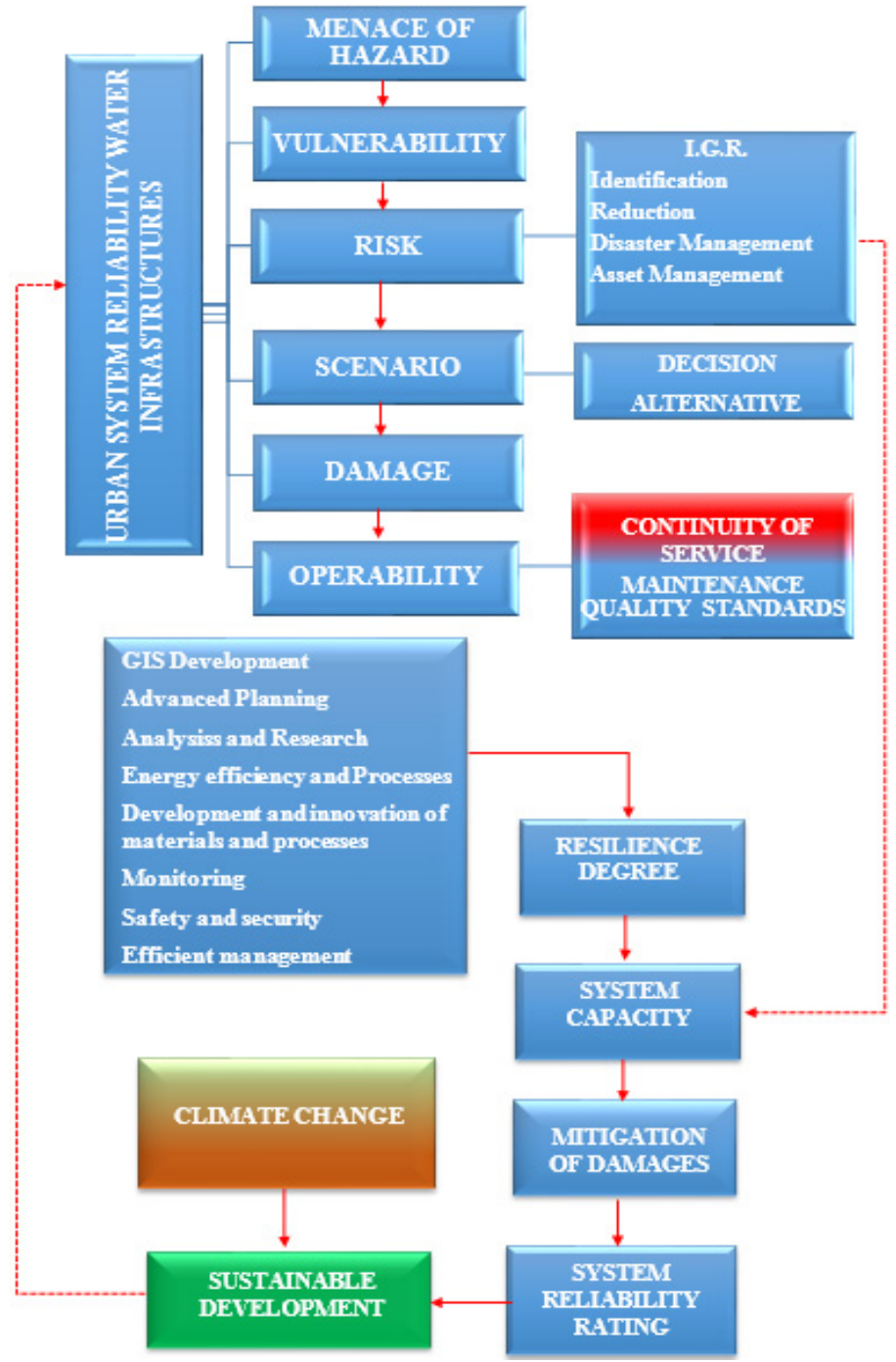

Figure 1: General diagram of the suggested management methodology and established milestones in relation to natural hazards (EMUASA).

In the previous sequential diagram, we indicate the IRM, that is, the Index for Risk Management that allows us to follow the implemented measures to improve 
the resilience of the system and, therefore, the reliability of said Hydraulic Infrastructures System [5-9].

The methodology that creates the suggested management model consists on the selection of the parameters that define the efficient operation of the urban hydraulic system, joining all the involved variables that characterise each type of risk. Thus, the values of the characteristic parameters that define the vulnerability and the estimated damage on the infrastructure has been obtained, in a way that integrates all the risk variables and that particularly defines each element or component of the facility. Along with the implementation of this model will be the planning and exploitation of the urban hydraulic infrastructure tool, which will also define the Plan of Hydrogeological Risks Management.

\section{Methodology}

The suggested management methodology, foundation of this research, consists on a comprehensive and general vision in relation to hydrogeological risks, both as a whole and individually, since, as it can be verified throughout this research, the different components of the indicated risks can overlap and converge generating new risks or incrementing the initial risk.

Likewise, different variables and parameters that define the indexes of vulnerability of the infrastructure are proposed for a first stage called 'Base or Inherent Vulnerability' that, as its own name indicates, establishes and reflexes the initial management model of the analysed Urban Hydraulic Infrastructure. This is because its physical characteristics and its management typology define the degree of initial vulnerability of the system on which we can perform interventions on certain components and/or systematically applying other integrated methodologies, since their application show the same transversality and that they interact at the same time or evolve at the same time, to a greater or lesser degree.

Another characteristic of the suggested management methodology is the necessity of having a reliable and 'sufficient' initial inventory, properly structured and periodically updated, this can be used as a source of real information for the development of the suggested management method. It will also create some scenarios that, even if they are only estimated, will contain the minimum required information to define the estimated hypothetical situation based on these possible scenarios and its live update with the flow of received information apart from studying the existing management typology of the system. In the initial stage, already defined, or 'pre-event' status of the system, we define its capacity to face a hydrogeological event and obtain the initial degree of vulnerability of the essential components of the system, both comprehensively and individually; we refer to the second stage, representative of the different selected hydrogeological risks that, after their individual or combined analysis, depending of the casuistry arising from the event, will generate additional vulnerabilities that are called extrinsic or risky and that will determine the interventions to carry out on the system.

Once the definition of this second stage is finished and the possible scenarios are specified and updated, with the upcoming live information, the definition of 
the vulnerability degree, the percentages of losses and the degree of affectation of the urban hydraulic system will be completed [10-12].

At this point, we will have all the minimum information required to act on the system and to make, thus, the more adequate decisions. The final objective is to 'guarantee' the normal functioning of the System and the maintenance of the standards of quality of service thanks to:

- The establishment of measures to reduce system vulnerability, subject to the suggested hydrogeological risk typology.

- The adaptation and analysis of the system vulnerability in relation to the new situations provoked by continuing climate change.

- The control and management of the defined hydrogeological risks that act on urban hydraulic infrastructures and the evolution of the resilience degree.

Creating the initial model, we can evolve towards a final dynamic model, depending on the verification of the process, and towards the calibration of all the suggested parameters, whose origin are the defined variables and the proposed parameters of the initial model that has been analysed and proposed.

Of all the aspects that converge on the differential fact, regarding the rest of the management models, we could highlight the degree of content and the quality of the starting information since two visions converge in its definition: the determinist and the possibilistic, which complement each other to obtain estimated scenarios with a reasonable degree of authenticity that adapt themselves in real time with the live information they receive.

The possibility of the integration of a GIS compatible system in a multi-risks environment and the real possibility of implementation in any area of the planet add value to this research. Likewise, and given the transversality of the suggested research, its implementation involves the improvement of processes, research and innovation, the development and proposal of new composite materials, as well as resilient and efficient devices, from an energetic and environmental point of view.

Now, we will describe schematically each one of the stages of the suggested methodology, its sequential development, its objectives and its evolution in real time for the decision-making process.

\section{Results and discussion}

The analysis of the suggested management model establishes the following reference variable according to the risk typology and the specific infrastructure of an Urban Hydraulic System that, in this case, for instance, are limited to the risks of flooding and earthquake.

Once the characteristic variables and parameters depending on the suggested analysed scenario are established, we locate the risk areas and, since the vulnerability of the infrastructure in each area has already been defined, we establish a gradation or risk level both locally and comprehensively through its deliberation taking into account the criteria established in the model [13]. As it, is 


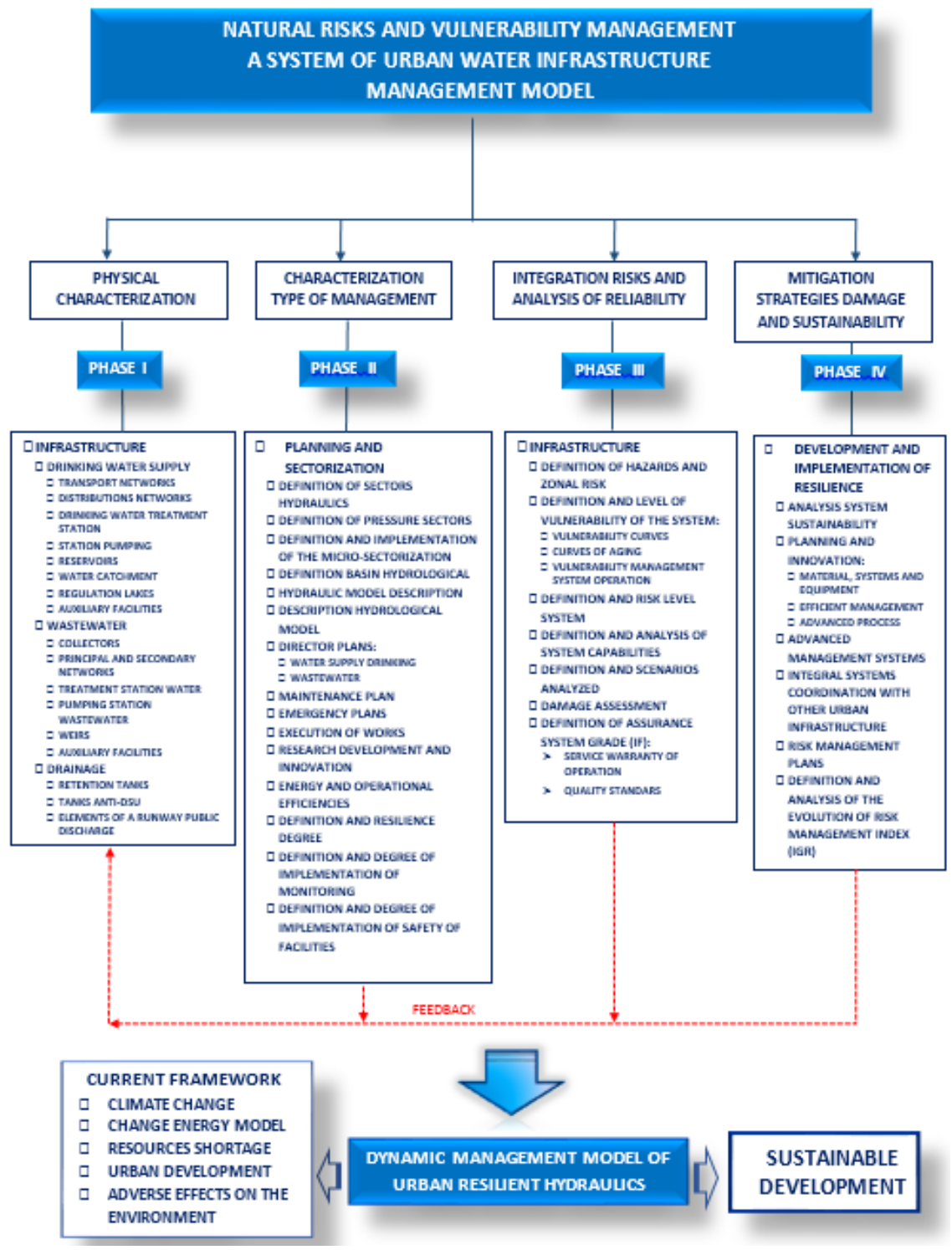

Figure 2: Diagram of the different stages of development of the suggested methodology (EMUASA). 
Table 1: Characterization of the urban hydraulic Infrastructures System and the representative variables of Flooding and Earthquake Risks. (*) The moment magnitude $(\mathrm{Mw})$ is recommend for $>6.9$ earthquakes (National Earthquake Information Center, USA). EMUASA.

\begin{tabular}{|c|c|}
\hline \multicolumn{2}{|c|}{ CHARACTERIZATION OF HYDRAULIC SYSTEM } \\
\hline \multicolumn{2}{|c|}{ Area: Supplying } \\
\hline \multicolumn{2}{|l|}{ Fields of the area: } \\
\hline Hydraulic sector & Pressure area \\
\hline Hydraulic sub-sector & Micro-sectors \\
\hline \multicolumn{2}{|c|}{ Area: Sanitation and Drainage } \\
\hline \multicolumn{2}{|c|}{ Fields of the area: } \\
\hline Hydraulic basin & Drainage basin \\
\hline Hydraulic sub-basin & Peri-urban drainage basin \\
\hline
\end{tabular}

\begin{tabular}{|l|l|}
\hline \multicolumn{1}{|c|}{ FLOODING RISK } & \multicolumn{1}{c|}{ EARTHQUAKE RISK } \\
\hline Reference variables: & \\
\hline $\begin{array}{l}\text { Return period. Reference time }(10,50,100, \\
500 \text { years })\end{array}$ & Seismic Intensity (MMI, EMS-98) \\
\hline Flood zone $\left(\mathrm{km}^{2}\right)$ & $\begin{array}{l}\text { Peak Ground Acceleration }(\mathrm{PGA}) \\
\text { 'horizontal component' }\left(\mathrm{g}=9.81 \mathrm{~m} / \mathrm{s}^{2}\right)\end{array}$ \\
\hline Draft $(\mathrm{m})$ & Basic Ground Acceleration $\left(\mathrm{a}_{\mathrm{b}}\right) \mathrm{g}$ \\
\hline Runoff direction & Local Contribution Coefficient $(\mathrm{K})$ \\
\hline Speed runoff flow $(\mathrm{m} / \mathrm{s})$ & Peak Ground Velocity $(\mathrm{PGV}) \mathrm{cm} / \mathrm{s}$ \\
\hline Precipitation $\left(\mathrm{mm}, 1 / \mathrm{m}^{2}\right)$ & Peak Ground Displacement $(\mathrm{PGD})$ \\
\hline Runoff coefficient $(\mathrm{C})$ & Moment magnitude $(\mathrm{Mw})(*)$ \\
\hline Time of Concentration $(\mathrm{Tc}) \mathrm{min}$ & Seismic moment $(\mathrm{Mo})(\mathrm{N} \cdot \mathrm{m})$ \\
\hline Precipitation threshold $(\mathrm{Po}) \mathrm{mm}$ & Maximum runoff flow $\left(\mathrm{Q}_{\mathrm{max}}\right) \mathrm{l} / \mathrm{s}, \mathrm{m}{ }^{3} / \mathrm{h}$ \\
\hline Maximum flow runoff $\left(\mathrm{Q}_{\max }\right) \mathrm{l} / \mathrm{s}, \mathrm{m}^{3} / \mathrm{h}$ & \\
\hline
\end{tabular}

indicated in the diagram of development of the management methodology (Figure 1), the vulnerability of the drinking water network in relation to the seismic risk can have different forms depending on the reference parameters and the authors. In the studied case, the repair rate of the distribution network has a similar ratio to the typology of maintenance, the pipes degree of ageing and the parameter of seismic speed expected according to the seismic characteristics of the area. Although there are, other factors that can change said rate, such as the local effect and the combination of concurrent risks.

The suggested maintenance typology is based on the research of the World Bank Institute (Kingdom et al. [15]), although it is modified by the present research in the following terms: 
Table 2: Suggested typologies of maintenance for the drinking water distribution network, adapted EMUASA.

\section{PHASE I}

\begin{tabular}{|l|l|l|}
\hline DEGREE 1 & D - very poor & $\begin{array}{l}\text { Inefficient use of the resources; priority need of implementing an } \\
\text { NRW reduction program. }\end{array}$ \\
\hline DEGREE 2 & C - poor & $\begin{array}{l}\text { Acceptable in the event of cheap and abundant water; with } \\
\text { intensification of the NRW reduction efforts. }\end{array}$ \\
\hline DEGREE 3 & C-average low & $\begin{array}{l}\text { The accuracy of the management is considered, the leak control } \\
\text { on the improvement of assets and a higher degree of preventive } \\
\text { maintenance. }\end{array}$ \\
\hline
\end{tabular}

PHASE II

\begin{tabular}{|l|l|l|}
\hline DEGREE 4 & B - average high & $\begin{array}{l}\text { The management of the evolution of pressure and consumption } \\
\text { is considered, as well as the exhaustive leak control on the } \\
\text { improvement of assets and an evolution in the degree of } \\
\text { predictive management. }\end{array}$ \\
\hline DEGREE 5 & B - good & $\begin{array}{l}\text { Identification and analysis of loss reduction. Economic } \\
\text { research. }\end{array}$ \\
\hline DEGREE 6 & A - good advanced & $\begin{array}{l}\text { Efficient management of the system. The analysis of loss } \\
\text { reduction may be uneconomic, it is necessary to identify and } \\
\text { select the cost effective improvements. }\end{array}$ \\
\hline
\end{tabular}

As indicated in the previous table, 6 degrees of maintenance of the urban hydraulic Infrastructures System are proposed, based on the recommendations adapter from the World Bank Institute (Kingdom et al. [15]). Said maintenance degrees evolve with time in two clearly differentiated phases that will enable an efficient management and the resilience of the System.

- A corrective maintenance or a minimum threshold of maintenance is proposed, estimated between the $5 \%$ and the $10 \%$ that will occur in any circumstance.

- Each maintenance typology will create an intrinsic vulnerability that will join with the vulnerability of the different components and facilities of the Urban Hydraulic Infrastructure, obtaining, this way, the total intrinsic vulnerability of the System under normal conditions of operation (preevent).

- Once the total intrinsic vulnerability of the system is obtained, the extrinsic vulnerability will be analysed depending on the nature of the natural hazard. This will create the Degree of Reliability of the Hydraulic System as a whole. 


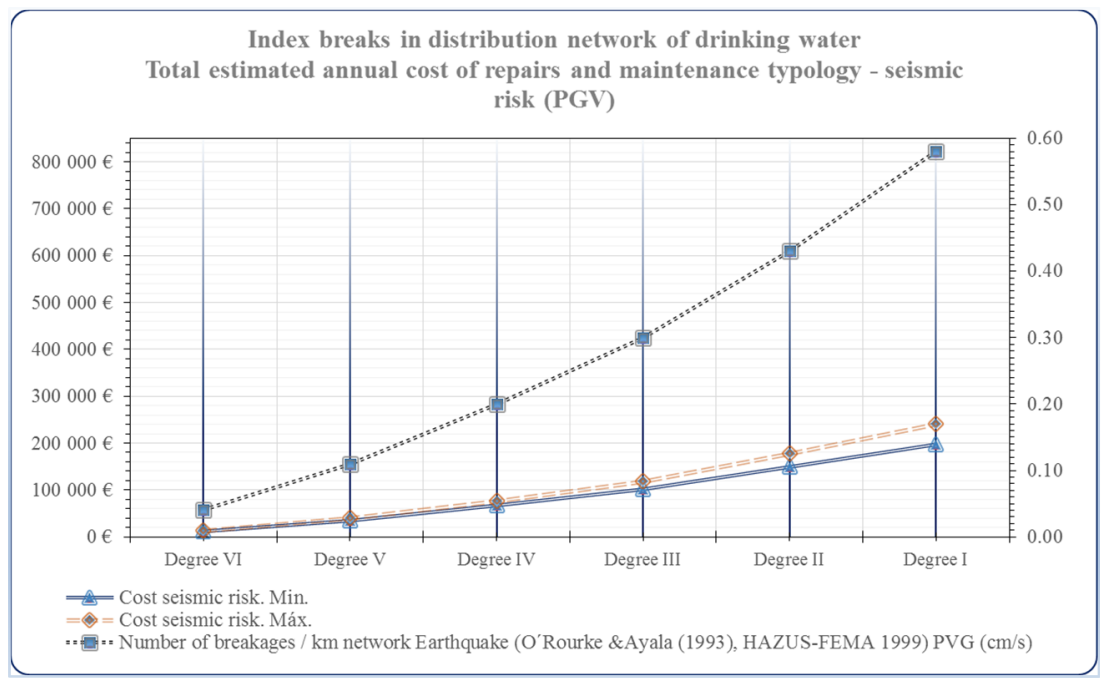

Figure 3: Representation of the index of breaking on the drinking water distribution network of a Spanish town and the suggested typology of maintenance, in relation to PGV, according to the adapted HAZUSFEMA methodology (EMUASA).

As an example of the proposed application, we chose the district of Zarandona, in Murcia, as an example, whose characterisation is the following.

\subsection{Drinking water supply}

Zarandona Hydraulic Area and the sub-areas included in it. EPANET MODEL.

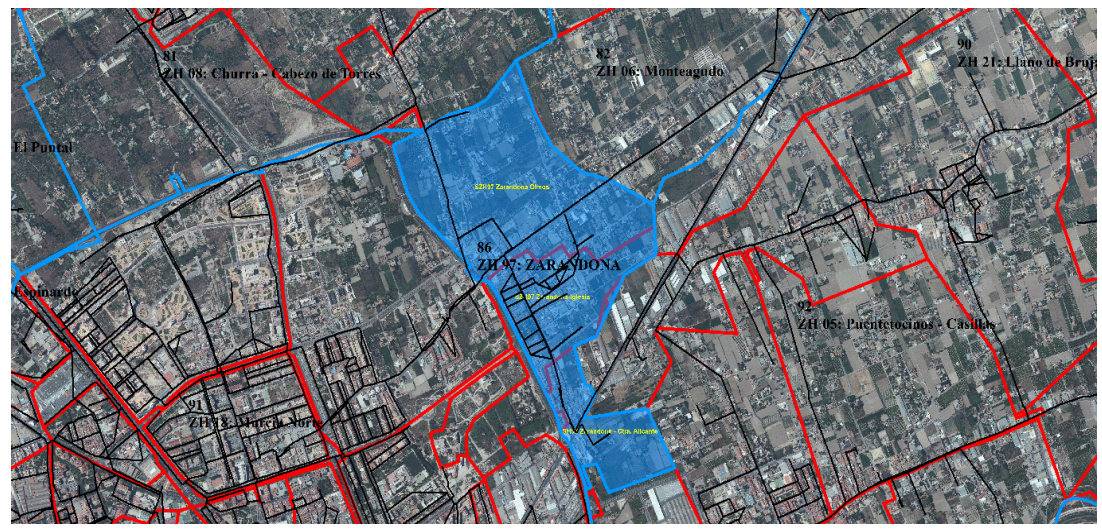

Figure 4: Representation of different hydraulic areas and sub-areas in Zarandona (Murcia) generated by the program EPANET (EMUASA). 


\subsection{Wastewater and drainage}

Hydraulic basin called 'GRV Zarandona' and its correspondent sub-basins. Model SWMM.

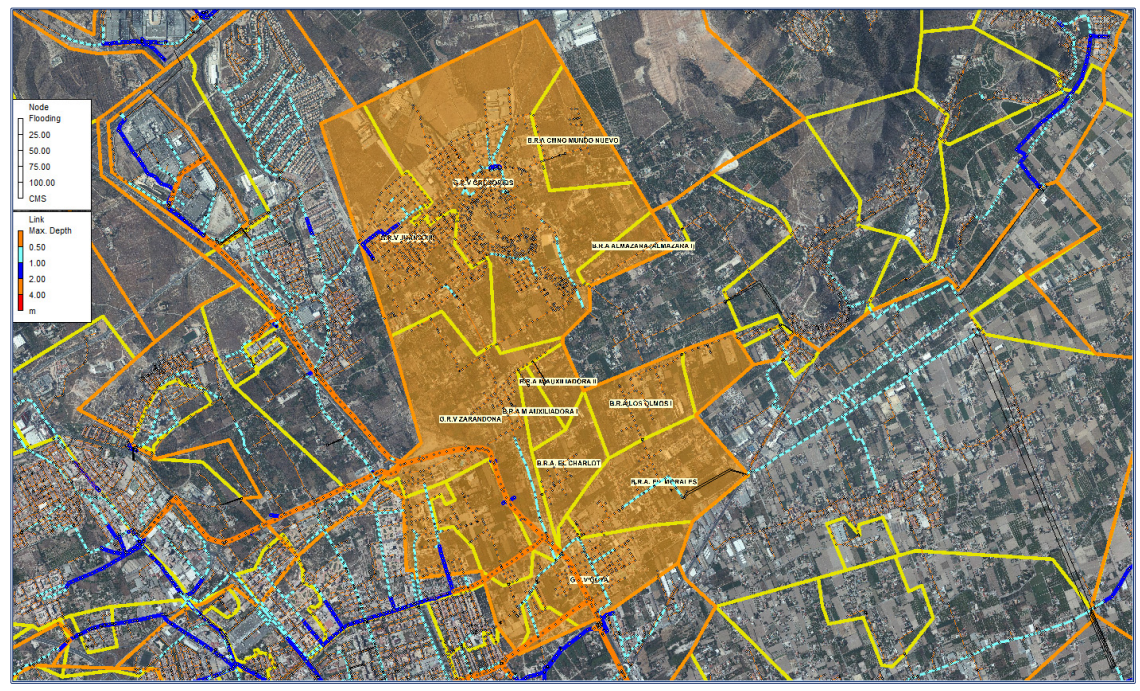

Figure 5: Representation of different hydraulic basins and sub-basins in Zarandona (Murcia) generated by the program SWMM (EMUASA).

\section{Conclusions}

The analysis of the variables and distinctive parameters of the system of urban hydraulic infrastructures needs an analytical description, apart from a structuration of its different essential components to respond to new challenges. To this end, we suggest the definition of an advanced management model, sustainable and integrated in the urban area.

With this objective, the analysis, development and implementation of the comprehensive resilience of the system are suggested. Likewise, we propose to use new techniques and efficient procedures, new materials and equipment adapted to the current requirements that allow the adaptation of the hydraulic infrastructure to the new scenarios of climate change, increasing the system's sustainability and efficiency, on a framework of circular economy where the lack of resources, the increase of urban population and the environmental balance are the 'cornerstone' of sustainable human development. In this changing environment, the efficient management of the urban hydraulic infrastructure poses many challenges for the ordinary operation that are increased in the case of extraordinary catastrophic natural events to which the system must react ensuring a minimum degree of 'acceptable' service.

The performed methodological research suggests the variables and parameters that define the Urban Hydraulic System and the representative parameters, 
essential to obtain the vulnerability of the different components of said system correlating said characterisation with the variables and parameters that define the suggested natural risks that, in this case, are the risk of flooding and the seismic risk. Additionally, different procedures and methodologies to define the vulnerabilities of the components, the equipment and the management of the System are proposed, defining fragility and ageing curves adapted to local singularities.

We add thematic maps with relational database that will support the definition of the possible risk scenarios, the reduction and evaluation of expected damage, apart from providing a base of essential information to guarantee the system operation and the maintenance of the water quality standards. With this management model, we provide the System with an essential tool to support the decision-making process before, during and after the natural catastrophic event, allowing the planning of the operation in order to improve the System's resilience.

Its application and evolution time will allow the continuous improvement of urban hydraulic infrastructures and its sustainable management, reducing the system's vulnerability and the existing risk, suggesting the development of advanced procedures of efficient management, adding new, more efficient materials that increase resilience in a climate change scenario and with a development model with significant environmental, economic and social imbalances. For this matter, different milestone, are proposed, summarised in the following considerations:

- Description of the physical characteristics of urban water hydraulic infrastructure.

- Characterisation of the system's effectiveness.

- Definition of defining variables of the system.

- Record of operational events of the system.

- Analysis, definition and evaluation of the degree of inherent vulnerability of the hydraulic system.

- Analysis and definition of the degree of intrinsic reliability of the system.

- Planning and design of the essential elements of the urban hydraulic infrastructure.

- Analysis of the interaction with other vital infrastructures.

- Research of variables external to the urban hydraulic system.

- Acting proposals to implement and/or increase the resilience of the urban hydraulic infrastructure.

- Proposal of defining variables of the system.

- Analysis and characterisation of the area.

- Research, development and analysis of the defining variables of the system and their correlation to the typology of the expected hydrogeological risk.

- Analysis of hydrogeological risks in the area and its integration in the definition of the resilient hydraulic system.

- Integration of database defining the system and the thematic base of hydrogeological risks. 
- Definition, analysis and interaction of hydraulic models and of system management, with hydrologic models and other specific models that define the hydrogeological risks in the area.

- Definition and implementation of hydrogeological risks thematic maps of the area

- Evaluation of predictable scenarios and damage assessment.

- Proposal of operational alternatives of the system.

- Development and implementation of a Plan of Natural and/or Hydrogeological Risks Management in the Area, when necessary.

Defining the constituent components of the urban hydraulic system, analysing its vulnerability from the suggested variables and parameters and the indexes that define them, apart from its management typology with a comprehensive vision, we obtain an essential tool for the decision-making process and the guarantee of the success of the operation and the maintenance of quality standards of the system. To that end, an adequate platform is essential to operate and analyse the information that assimilates all the presented topics.

\section{Notation}

$C \quad=$ Runoff coefficient.

$P G A=$ Peak ground acceleration $\left(\mathrm{g}\right.$ or $\left.\mathrm{m} / \mathrm{s}^{2}\right)$.

$P G V \quad=$ Peak ground velocity $(\mathrm{cm} / \mathrm{s}$ or $\mathrm{m} / \mathrm{s})$.

$P G D=$ Peak ground displacement $(\mathrm{cm}$ or $\mathrm{m})$.

Qmax $=$ Maximum flow runoff $\left(\mathrm{m}^{3} / \mathrm{s}\right.$ or $\left.\mathrm{m}^{3} / \mathrm{h}\right)$.

\section{Acknowledgements}

The authors wish to thank to EMUASA its collaboration in the carrying out of this study, and in particular to its General Manager, José Albaladejo Guillén, for his great disposition to the project, without which this study would not have been possible.

\section{References}

[1] ATC-13 (Applied Technology Council) Earthquake Damage Evaluation Data for California. Redwood City, CA: Applied Technology Council, 1985.

[2] ATC-25 (Applied Technology Council) A model methodology for assessment of seismic vulnerability and impacts distribution of water supply systems. Report No: ATC-25-1, Redwood City, C.A., 1992.

[3] Akkar S. and Bommer J.J. Empirical equations for the prediction of PGA, PGV and spectral accelerations in Europe, the Mediterranean Region and the Middle East. Seismological Research Letters. 81(2): 195-206, 2010.

[4] Esposito S., Iervolino I. PGA and PGV spatial correlation models based on European multievent datasets. Bulletin of the Seismological Society of America 101(5): 2532-2541, 2011a. 
[5] Cardona O.D., Ordaz M.G., Marulanda M.C., Barbat A.H. "Estimation of probabilistic seismic losses and the public economic resilience - An approach for macroeconomic impact evaluation". Journal of Earthquake Engineering. 12(S2): 60-70, 2008.

[6] Cardona O.D., Ordaz M.G., Yamn L.E., Marulanda M.C., Barbat A.H. "Earthquake loss assessment for integrated disaster risk management". Journal of Earthquake Engineering. 12(S2): 48-59, 2008a.

[7] Carreño M. L. Innovative techniques for seismic risk assessment and management in urban centers ante and ex post actions ex. doctoral thesis. Polytechnic University of Catalonia. Barcelona, 2006.

[8] Franchin P. (ed.) Methodology for systemic seismic vulnerability assessment of buildings, infrastructures, networks and socio-economic impacts. SYNER-G Reference Report 1, Publications Office of the European Union, ISBN 978-92-79-28975-0. 2, 2013.

[9] SRMLIFE Development of a global methodology for the vulnerability assessment and risk management of lifelines, infrastructures and critical facilities. Application to the metropolitan area of Thessaloniki. Research Project, General Secretariat for Research and Technology, Greece, 20032007.

[10] Barbat A.H., Cardona O.D. "Vulnerability and disaster risk indices from engineering perspective and holistic approach to consider hard and soft variables at urban level", 2003.

[11] Barbat A.H., Carreño M.L., Pujades L.G., Lantada N., Cardona O.D., Marulanda M.C. "Seismic vulnerability and risk evaluation methods for urban areas. A review with application to a pilot area". Structure and Infrastructure Engineering, 2009.

[12] Cardona O.D. "The need for rethinking the concepts of vulnerability and risk from a holistic perspective: A necessary review and criticism for effective risk management". In Mapping Vulnerability: Disasters, Development and People. G. Banko, G. Frerks, D. Hilhorst Eds. Earthscan Publishers. London, UK, 37-51, 2004.

[13] BID/IDEA. National University of Colombia. Manizales. Risk Indicators Program and Management. 2013. Available at: http://idea.unalmzl.edu.co. (accessed June 15, 2016).

[14] Rodriguez Avellaneda A.H., Civil Engineer, Telecommunications specialist. Thesis "Analysis and evaluation of seismic risk in lifelines. Bogotá D.C. Case study”. N. University of Colombia, 2011.

[15] Kingdom B., Liemberger R., Marin P. The World Bank Group, Water Supply and Sanitation Sector Board Discussion Paper Series, Paper No. 8, The Challenge of Reducing Non-Revenue Water (NRW) in Developing Countries. How the Private Sector Can Help: A Look at Performance-based Service Contracting, December 2006. 